\title{
$\mathrm{Bit}$ 설계형상의 굴진성능에 관한 연구
}

\author{
김광희 ${ }^{*}$, 이윤영
}

${ }^{1}$ (재)인천테크노파크

\section{A Study on Penetration Performance of Bit Design Geometry}

\author{
Kwang-hee Kim $^{1^{*}}$ and Yun-young Lee $^{1}$ \\ ${ }^{1}$ Incheon Technopark
}

요 약 본 연구에서는 지반시추용 드릴비트의 설계를 검증하기 위해 유한요소 해석을 수행하였다. 드릴비트 해석결 과와 실제 굴진시험장비의 실험결과와 비교하여 해석의 타당성을 검증하였다. 본 연구를 통해 드릴비트의 다양한 형 상, 재료 물성치 선정을 위해 유한요소해석을 활용하여 실제 실험에 소요되는 시간 및 비용 절감이 가능할 것으로 기 대된다.

\begin{abstract}
In this study, we carried out finite element analysis for drill bit design on ground boring. We verified analysis between drill bit analysis results and experiment results of test machine. From the study, the results expect that time and cost reduction for experiment using finite element analysis for determination on drill bit geometry and material property.
\end{abstract}

Key Words : Drill Bit, Finite Element Analysis, Ground Drilling, Penetration Analysis

\section{1. 서론}

광산 및 지반시추용 드릴비트 공구시장은 연간 3 조원 규모로 초기 초경을 사용한 Surface Bit가 연암부의 시추 분야에 사용되었으며, 이후 인조 다이아몬드 개발로 대부 분 시추분야에 사용되어지고 있다. 현재 다이아몬드 드릴 비트의 국내 기술수준은 주로 중경암 굴착에만 사용되는 Impregnated Bit 공구가 $95 \%$ 이상 생산되고 있으나 경암 이나 점성재질의 암석 굴착시에는 굴착성능이 급속히 감 소하는 경향을 나타내어 기술개발이 요구되고 있다. 본 연구에서는 중경암 지반 굴착에 사용되며 금속분말과 다 이아몬드의 혼합 소결체를 Steel Body에 접합한 Impregnated Bit, PCD Bit의 다이아몬드 입도, 분포, 돌출 량과 금속분말성분 등에 의해 절삭성이 좌우되는 것을 형상설계 해석을 통하여 고성능 드릴비트의 개발을 하고 자 한다.

\section{2. 지반시추용 드릴비트 연구동향}

일반 가공용 공구에 대한 유한요소해석은 관련연구 [1-4]가 수행되었으며, 지반시추용 드릴비트 비트형상에 대한 실험 및 이론적 연구[5-8]는 있었으나 지반시추용 드릴비트 전산해석에 대한 연구는 거의 없는 실정이다.

\section{3. 해석 방법}

\section{1 응력해석}

지반시추용 드릴비트 2가지 type(Impreganted Bit, $\mathrm{PCD} \mathrm{Bit})$ 에 대한 공구 특성을 검증하기 위해 시뮬레이션 을 이용하여 응력해석을 수행하였다. 표 1 은 전산해석에 필요한 기본 설정 데이터이다. 그림 1 은 드릴비트 (Impreganted Bit) 3가지 type에 대한 메시모델 및 응력해 석을 수행한 결과이다. 전산 시뮬레이션은 비선형 해석소 프트웨어인 AutoDyn을 이용하여 수행하였다.

\footnotetext{
${ }^{*}$ Corresponding Author : Kwang-hee Kim

Tel: +82-10-2825-4052 email: kkhkbs@hanmail.net

접수일 12년 09월 10 일 수정일 12년 09월 26일 게재확정일 12년 10월 11일
} 
[표 1] 전산해석 물성치

[Table 1] Material Properties of analysis (a) 드릴비트 물성치

\begin{tabular}{|c|c|}
\hline 항목 & 드릴비트 \\
\hline Density & $8,820 \mathrm{~kg} / \mathrm{m}^{3}$ \\
\hline Shear Modulus & $8.26 \mathrm{E}+10 \mathrm{~Pa}$ \\
\hline
\end{tabular}

(b) 화강암 물성치

\begin{tabular}{|c|c|}
\hline 항목 & 화강암 \\
\hline Density & $8,930 \mathrm{~kg} / \mathrm{m}^{3}$ \\
\hline Compressive Strength & $1.08 \mathrm{E}+8 \mathrm{~Pa}$ \\
\hline Shear Modulus & $2.206 \mathrm{E}+10 \mathrm{~Pa}$ \\
\hline
\end{tabular}

(c) 지반시추조건 설정

\begin{tabular}{|c|c|}
\hline 항목 & 시추조건 \\
\hline RPM & 500 \\
\hline Feed & $6 \mathrm{~cm} / \mathrm{min}$ \\
\hline
\end{tabular}

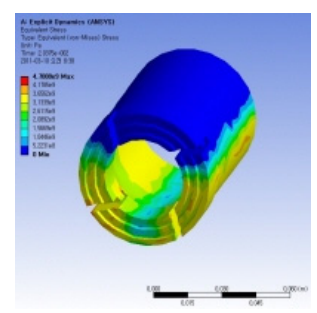

(a) Case 1

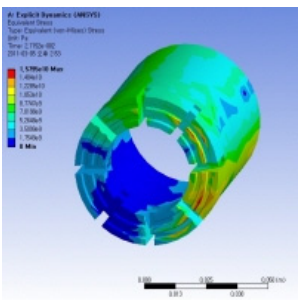

(c) Case 3

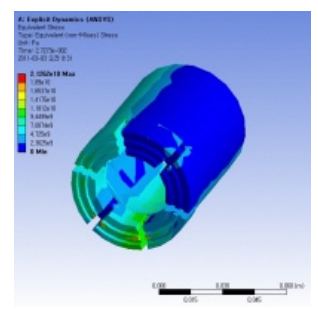

(b) Case2
그림 1] Impregnated Bit 응력해석

[Fig. 1] Stress analysis of Impregnated Bit

\section{2 굴진성능 해석}

Impregnated Bit 해석모델에서 전산해석 시간을 절감 하기 위해 Bit 형상(3종)을 전체형상에서 실제 굴진에 활 용되는 형상만 간략화하여 모델링 하였다. 그림 2 는 Impregnated Bit 암반의 mesh 수는 기본크기 $(0.0015 \mathrm{~mm})$ 를 기준으로 250,000 개로 설정하였다.

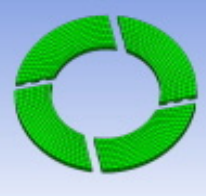

(a) Case 1

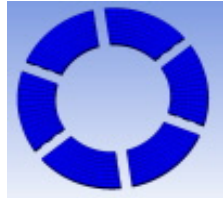

(b) Case 2

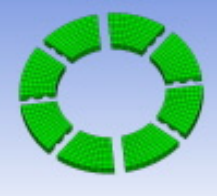

(c) Case3
[그림 2] Impregnated Bit 메시모델

[Fig. 2] Mesh Model of Impregnated Bit

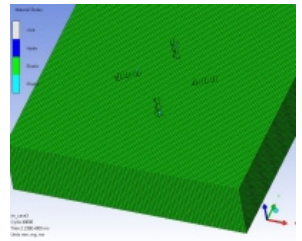

(a) 40,000 cycle

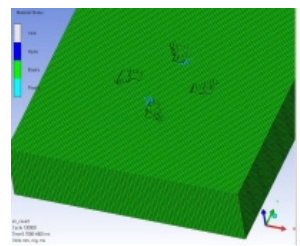

(c) 120,000 cycle

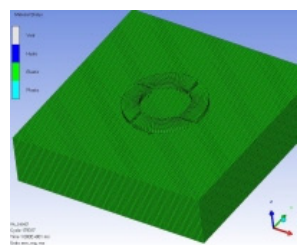

(e) $10 \mathrm{~ms}$ (비트포함)

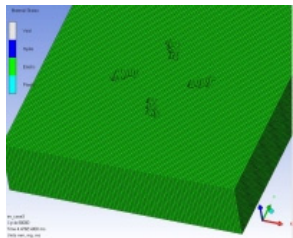

(b) 80,000 cycle

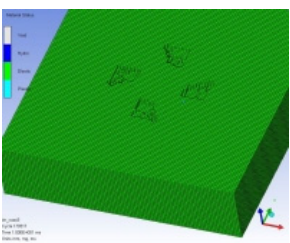

(d) $10 \mathrm{~ms}$
[그림 3] Impregnated Bit(Case1) 굴진 해석 결과 [Fig. 3] Penetration Analysis of Impregnated Bit(Case1)

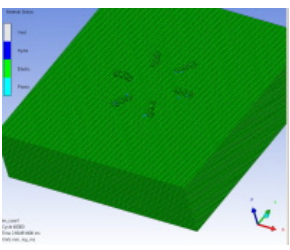

(a) 40,000 cycle

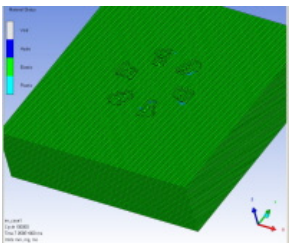

(c) 100,000 cycle

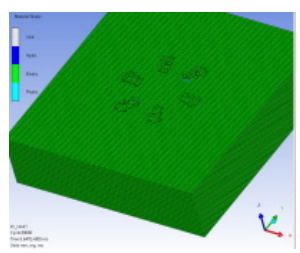

(b) 80,000 cycle

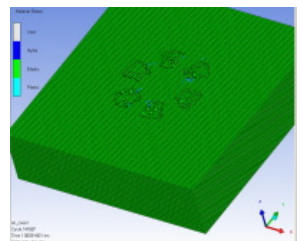

(d) $10 \mathrm{~ms}$ 


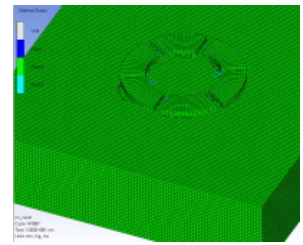

(e) $10 \mathrm{~ms}$ (비트포함)

[그림 4] Impregnated Bit(Case2) 굴진 해석 결과

[Fig. 4] Penetration Analysis of Impregnated Bit(Case2)

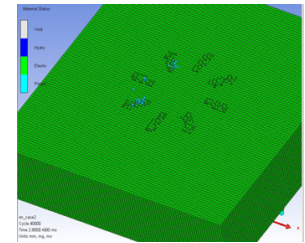

(a) 40,000 cycle

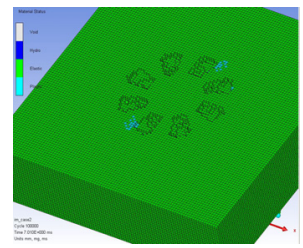

(c) 100,000 cycle

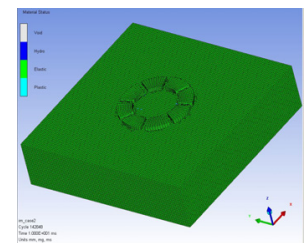

(e) $10 \mathrm{~ms}$ (비트포함)

[그림 5] Impregnated Bit(Case3) 굴진 해석 결과

[Fig. 5] Penetration Analysis of Impregnated Bit(Case3)

그림 3 그림 5는 Impregnated Bit 3가지 case에 대한 시간에 따른 해석결과를 보여주며, Impregnated Bit의 굴 진성능해석은 $10 \mathrm{~ms}$ 기준으로 하여 mesh 탈락 개수를 많 은 것을 굴진성능이 우수한 것으로 평가하여 Case3(8분 할 요철)의 형상설계안을 제안하였다.

[표 2] Impregnated $\mathrm{Bit}(\mathrm{Case} 1)$ 굴진 결과 [Table 2] Result of Impregnated Bit(Case1)

\begin{tabular}{|c|c|c|c|}
\hline $\begin{array}{c}\text { Time } \\
(\mathrm{ms})\end{array}$ & cycle & mesh 수 & $\begin{array}{c}\text { mesh } \\
\text { 탈락개수 }\end{array}$ \\
\hline- & 0 & 250,000 & 0 \\
\hline 1.12 & 20,000 & 249,904 & 96 \\
\hline 2.24 & 40,000 & 249,834 & 166 \\
\hline 3.36 & 60,000 & 249,780 & 220 \\
\hline 4.48 & 80,000 & 249,728 & 272 \\
\hline
\end{tabular}

\begin{tabular}{|c|c|c|c|}
\hline 5.59 & 100,000 & 249,670 & 330 \\
\hline 6.71 & 120,000 & 249,629 & 371 \\
\hline 7.82 & 140,000 & 249,568 & 432 \\
\hline 10 & 179,317 & 249,471 & 529 \\
\hline
\end{tabular}

[표 3] Impregnated Bit(Case2) 굴진 결과

[Table 3] Result of Impregnated Bit(Case2)

\begin{tabular}{|c|c|c|c|}
\hline $\begin{array}{c}\text { Time } \\
(\mathrm{ms})\end{array}$ & cycle & mesh 수 & $\begin{array}{c}\text { mesh } \\
\text { 탈락개수 }\end{array}$ \\
\hline- & 0 & 250,000 & 0 \\
\hline 1.41 & 20,000 & 249,818 & 182 \\
\hline 2.82 & 40,000 & 249,672 & 328 \\
\hline 4.24 & 60,000 & 249,509 & 491 \\
\hline 5.65 & 80,000 & 249,397 & 603 \\
\hline 7.06 & 100,000 & 249,232 & 768 \\
\hline 8.47 & 120,000 & 249,094 & 906 \\
\hline 10 & 141,687 & 248,944 & 1,056 \\
\hline
\end{tabular}

[표 4] Impregnated Bit(Case3) 굴진 결과

[Table 4] Result of Impregnated Bit(Case3)

\begin{tabular}{|c|c|c|c|}
\hline $\begin{array}{c}\text { Time } \\
(\mathrm{ms})\end{array}$ & cycle & mesh 수 & $\begin{array}{c}\text { mesh } \\
\text { 탈락개수 }\end{array}$ \\
\hline- & 0 & 250,000 & 0 \\
\hline 1.40 & 20,000 & 249,770 & 230 \\
\hline 2.81 & 40,000 & 249,598 & 402 \\
\hline 4.21 & 60,000 & 249,385 & 615 \\
\hline 5.61 & 80,000 & 249,252 & 748 \\
\hline 7.01 & 100,000 & 249,136 & 864 \\
\hline 8.41 & 120,000 & 249,989 & 1,011 \\
\hline 10 & 142,848 & 248,844 & 1,173 \\
\hline
\end{tabular}

\section{3 굴진성능 해석(PCD Bit)}

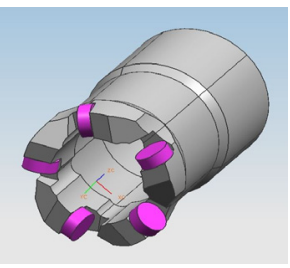

[그림 6] PCD Bit 3차원 설계 모델

[Fig. 6] 3D model of PCD Bit

$\mathrm{PCD}$ Bit의 3차원 설계 모델은 그림 6과 같이 모델링 하였다. 해석모델은 전산해석 시간을 절감하기 위해 $\mathrm{Bit}$ 전체형상에서 실제 굴진에 사용되는 $\mathrm{Bit}$ 각도에 따른 굴 진성능을 평가하기 위해 Case1(경사각=10), Case2(경사 각 $=0$ )형상을 모델링한 것을 그림 7에 나타내었다. 

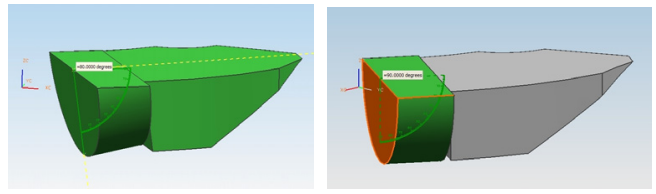

$<\operatorname{Case} 1$ (경사각 $=10$ ) $>$

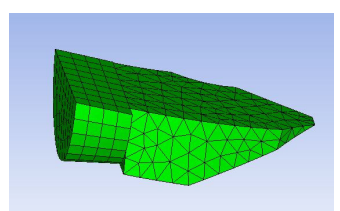

$<\operatorname{Case1}$ (경사각 $=10$ ) >

\section{$<$ Case 2(경사각 $=0)>$}

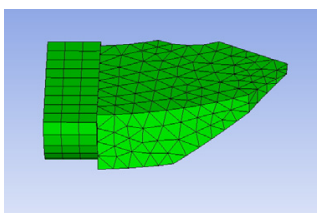

$<$ Case 2(경사각 $=0$ ) >

[그림 7] Bit각도에 따른 PCD Bit 형상

[Fig. 7] PDC Bit geometry according to angle

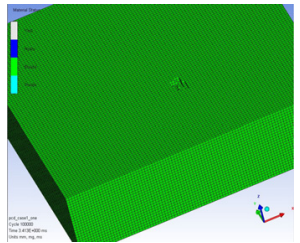

(a) 100,000 cycle

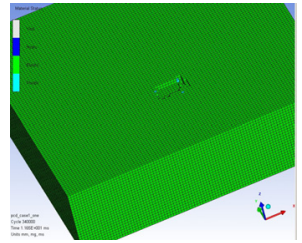

(c) 340,000 cycle

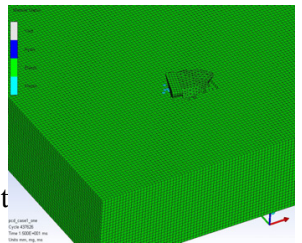

(e) $15 \mathrm{~ms}$ (Bit 포함)

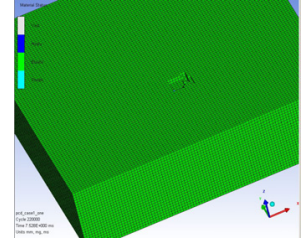

(b) 220,000 cycle

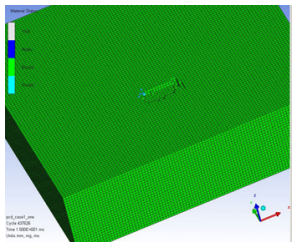

(d) $15 \mathrm{~ms}$

[그림 8] PCD $\operatorname{Bit}($ 경사각=10) 굴진 해석 결과

[Fig. 8] Penetration Analysis of PDC Bit(angle=10)

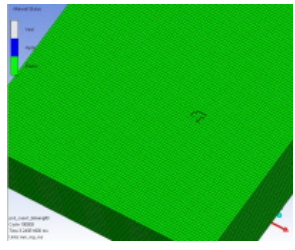

(a) 100,000 cycle

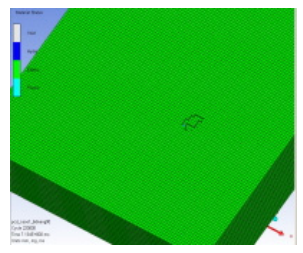

(b) 220,000 cycle

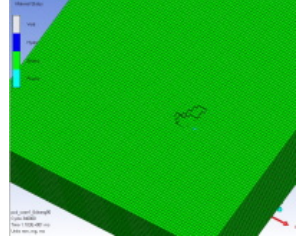

(c) 340,000 cycle

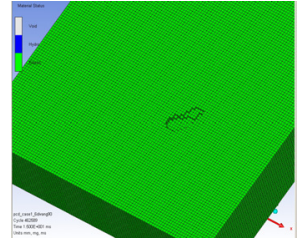

(d) $15 \mathrm{~ms}$

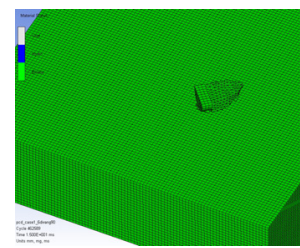

(e) $15 \mathrm{~ms}$ (Bit 포함)

[그림 9] PCD Bit(경사각=0) 굴진 해석 결과

[Fig. 9] Penetration Analysis of PDC Bit(angle $=0$ )

[표 5] PCD Bit(Case1) 굴진 결과

[Table 5] Penetration result of PCD Bit(Case1)

\begin{tabular}{|c|c|c|c|}
\hline $\begin{array}{c}\text { Time } \\
(\mathrm{ms})\end{array}$ & cycle & mesh 수 & $\begin{array}{c}\text { mesh } \\
\text { 탈락갯수 }\end{array}$ \\
\hline- & 0 & 250,000 & 0 \\
\hline 2.05 & 60,000 & 249,967 & 33 \\
\hline 4.10 & 120,000 & 249,948 & 52 \\
\hline 6.16 & 180,000 & 249,921 & 79 \\
\hline 8.22 & 240,000 & 249,900 & 100 \\
\hline 10 & 291,991 & 249,874 & 126 \\
\hline 12.30 & 360,000 & 249,846 & 154 \\
\hline 15 & 437,626 & 249,810 & 190 \\
\hline
\end{tabular}

[표 6] PCD Bit(Case2) 굴진 결과

[Table 6] Penetration result of PCD Bit(Case2)

\begin{tabular}{|c|c|c|c|}
\hline $\begin{array}{c}\text { Time } \\
(\mathrm{ms})\end{array}$ & cycle & mesh 수 & $\begin{array}{c}\text { mesh } \\
\text { 탈락갯수 }\end{array}$ \\
\hline- & 0 & 250,000 & 0 \\
\hline 1.95 & 60,000 & 249,990 & 10 \\
\hline 3.89 & 120,000 & 249,975 & 25 \\
\hline 5.84 & 180,000 & 249,961 & 39 \\
\hline 8.43 & 260,000 & 249,937 & 63 \\
\hline 10 & 308,386 & 249,921 & 79 \\
\hline 12.30 & 380,000 & 249,898 & 102 \\
\hline 15 & 462,589 & 249,876 & 124 \\
\hline
\end{tabular}

그림 8,9 및 표 5,6 의 결과와 같이, $\mathrm{PCD}$ Bit의 굴진 성능해석은 $15 \mathrm{~ms}$ 기준으로 하여 mesh 탈락 개수를 평가 하여 Case1(경사각) 형상설계안을 제안하였다.

\section{4. 해석과 굴진시험 분석}

\section{1 굴진시험 결과}

앞 절에서 드릴비트 전산해석 결과를 검증하기 위해 
그림 10 의 굴진시험평가 장비를 활용하여 분석하였다. 먼저, Imprgnated Bit에 4분할 사선, 6 분할 요철, 8 분할 요 철에 대한 굴진시험결과는 그림 11 과 같다. 8 분할요철 형 상이 타 형상보다 소모전류가 $1.42 \mathrm{~A}$ 로 작게 나타나 굴진 성능이 상대적으로 우수한 것으로 확인되었다. 이러한 결 과는 앞 절의 Imprgnated Bit 전산해석 결과와 동일하게 나타나 그림 12 와 같은 전산해석 타당성이 검증되었다.

먼저, PCD Bit에 경사삭 0도와 10 도에 대한 굴진시험 결과는 그림 13 과 같다. TIP 접합각도에 따라 경사각이 없는 0 도 보다는 10 도의 경사각이 있는 비트가 소모전류 가 작게 나타나 굴진성능이 상대적으로 우수한 것으로 확인되었다. 이러한 결과는 앞 절의 $\mathrm{PCD} \mathrm{Bit}$ 전산해석 결과와 동일하게 나타나 그림 14 와 같이 전산해석 타당 성이 검증됨을 확인할 수 있었다.

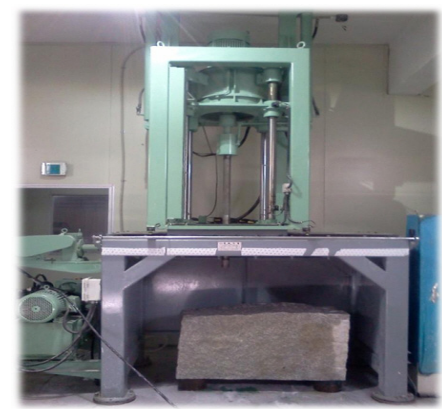

[그림 10] 굴진시험평가 장비

[Fig. 10] Machine for Peneration Test

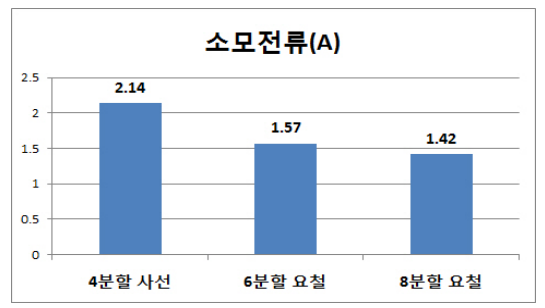

[그림 11] Imprgnated Bit 굴진 시험결과(소모전류)

[Fig. 11] Test result of Penetration(Current)

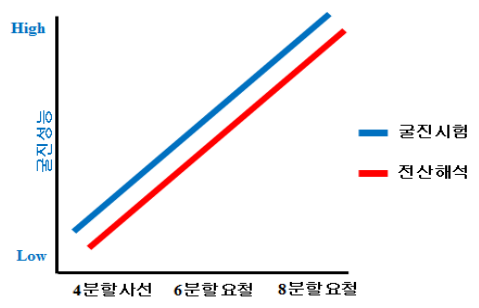

[그림 12] Impregnated Bit 해석 및 시험결과 비교

[Fig. 12] Comparison of analysis and test result

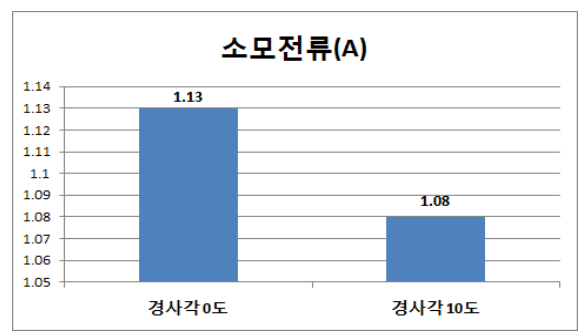

[그림 13] PCD Bit 굴진 시험결과(소모전류)

[Fig. 13] Test result of Penetration(Current)

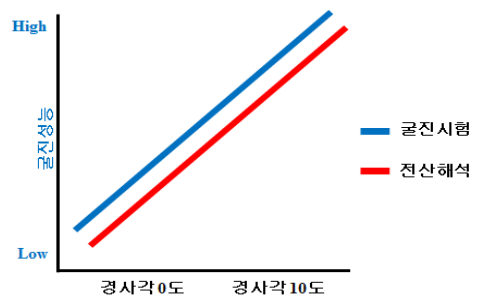

[그림 14] PCD Bit 해석 및 시험결과 비교

[Fig. 14] Comparison of analysis and test result

\section{5. 결론}

본 연구에서는 지반시추용 드릴비트의 설계 및 성능검 증을 위한 전산해석을 수행하여, 실제 암반굴진시험장비 결과와 비교 분석하여 다음의 결론을 얻었다.

1) Impregnated Bit 형상에 대한 굴진해석을 통해 Case3(8분할 요철)을 제안하였으며, 굴진시험평가 를 통해 타 설계안에 비해 우수한 성능을 검증하 였다.

2) PCD Bit 형상에 대한 굴진해석을 통해 Case1(경사 각 10 도)을 제안하였으며, 굴진시험 평가를 통해 성 능 검증하였다.

3) 향후 본 연구에 적용된 굴진해석기술을 통해 암반 특성에 따른 지반시추용 드릴비트 형상 설계에 적 용이 가능할 것으로 판단된다.

\section{References}

[1] S.C. Jung and K.W. Kim, "A study on Finite element analysis of tool deformation in End Milling", The Korea Academia-Industrial Cooperation Society Paper, Vol. 6, No. 1 pp.83-86, 2005.

[2] C.B. Wang, D.H. Song and Y.B. Park, "Finite element analysis of TEE forming for HDPE pipe", The Korea 
Academia-Industrial Cooperation Society Paper, Vol. 7, No.3, pp.298-307, 2006.

[3] H.J. Cho and T.I. Seo, "Tool deflection analysis using measured cutting forces in Micro end-milling", Korean Society for Precision Engineering Spring Conference paper, pp.211-212, 2010.

[4] K.W. Kim and T.K. Ahn, "A finite element analysis of the drilling process", Korean Society for Precision Engineering Spring Conference paper, pp.1055-1058, 2002.

[5] Y.S. Song, J.J. Choi and H.T. Park," "A study on operation development method through the appliction result TBM tunneling in the rock", The Korea Academia-Industrial Cooperation Society Paper, Vol. 9, No. 4, pp.1050-1058, 2008.

[6] C.J. Jackson and S.K. Ghosh. "On the Evlution of Drill-Bits Shapes", Jpurnal of Mechanical Working Technology, 18, pp.231-267, 1989.

[7] Tesuji Ohno and Hirokazu Karasawa, "Cost reduction of polycrystalline diamond compact bits through improved durability", Geothermics 31, pp. 245-262, 2002.

[8] V.B. Achanti and A.W. Khair. "Bit Geometry effects on failure characteristics of rock", Mining engineering Vol. 52, No.6 pp. 101-107, 2000.

\section{김 광 희(Kwang-hee Kim)}

[정회원]

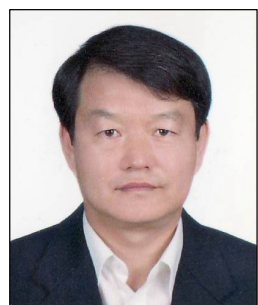

- 2005년 2월 : 국민대학교 대학원 기계설계공학과 (공학박사)

- 2012년 8월 현재 : (재)인천테크 노파크 기술혁신본부 본부장

<관심분야>

$\mathrm{CAD} / \mathrm{CAM} / \mathrm{CAE}$, 정밀가공, 최적설계 